\title{
Globalização do Mercado de Vinhos Finos e o Protagonismo Promocional das Redes Sociais
}

\section{Globalization of the Fine Wine Market and the Promotional Protagonism of Social Networks}

\author{
Míriam de Aguiar Barbosa \\ Possui graduação em Comunicação Social pela Universidade Federal de Minas \\ Gerais (1995), mestrado em Comunicação Social pela Universidade Federal de \\ Minas Gerais (1998), doutorado em Comunicação e Cultura pela Universidade de \\ São Paulo (2006) e pós-doutorado em Sociologia Econômica pelo intercambio \\ internacional entre CPDA/UFRRJ e UMR Innovation, França (CAPES). É coor- \\ denadora e docente do Curso de Comunicação Social, Habilitação: Publicidade e \\ Propaganda, da Universidade Veiga de Almeida, no Rio de Janeiro e Professora \\ Titular de Enologia da Faculdade Senac Rio. Trabalha também como professora \\ do MBA em Gestão Gastronômica e Hoteleira do Núcleo de Pós-graduação do \\ Senac-MG. Vem atuando desde 1998 na gestão e docência do Ensino Superior em \\ Comunicação Social, Gestão Cultural e Enogastronomia.
}

\section{RESUMO}

A Fruto de um estudo comparativo entre Brasil e França, este artigo analisa as mudanças em curso no mercado de vinhos finos, resultantes do processo de globalização e ajustes às novas realidades sociais e contextos diferenciados nos quais o produto se insere. A comunicação sobre o vinho, atualmente ampliada e diversificada pelas tecnologias digitais, multiplica consumidores e contribui para a formação de uma opinião especializada de contornos particulares. Aspectos como o perfil singular do mercado, a sensualidade e notoriedade associadas ao consumo do vinho, a perspectiva personalista das interações pelas redes sociais, além da demanda por renovação constante das mensagens veiculadas caracterizam e influenciam o teor dessa comunicação, crescentemente utilizada como ferramenta promocional da indústria vitivinícola.

Palavras-chave: comunicação; consumo; mercados de qualidade.

\section{ABSTRACT}

This article comes from a comparative research between brazilian and french fine wine markets, which analyses the changes and impacts of the globalization process upon the new social enviroments and distinct contexts, where the product lies on. The midiatic communication about wine, amplified and diversified by the digital technologies, multiplies consumers and contributes to a statement of a specialized and very particular opinion. Aspects as the singular profile of this market, the sensuality and notoriety related to the wine consumption, the personalistic perspective of social nets and the demand for continual renovation of the diffused messages denote the contents of this communication, that works as a promotional tool of the wine industry. Keywords: communication; consumption; quality markets. 


\section{Introdução}

Especialmente nas últimas três décadas, o mundo do vinho passou por profundas transformações. Assim como em inúmeros setores, a evolução das tecnologias de comunicação impulsiona a conexão entre produtores e consumidores e a organização de um mercado mais global. Mesmo estando ancorado profundamente na tradição, o setor do vinho busca seguir este movimento, em parte limitado por sua maior dependência de ciclos naturais e características de um produto agroalimentar. Há um avanço no ajuste entre os limites geofísicos e as demandas do processo de industrialização, no entanto, o vinho continua fortemente atrelado a representações simbólicas e identitárias, de certo modo contrastantes com a padronização inerente à estruturação de um mercado global.

Uma das ocorrências mais significativas para intensas transformações neste mercado foi a diminuição genérica do consumo interno de vinhos nos países nos quais era produto tradicionalmente bebido em grande quantidade, como França, Itália, Espanha e Argentina. A queda de mais de 50\% nas taxas de consumo per capita ${ }^{1}$, com várias crises de superprodução, pressionaram o mercado rumo a inovações tanto em termos de produção, quanto em termos de comercialização. Outro fator de crise são as mudanças de comportamento inter-geracionais em face de um produto identificado com valores de uma tradição alimentar mais regionalizada. (AGUIAR, 2015). Especialmente, a partir do período que se segue às grandes guerras mundiais, as novas gerações crescem em ambientes, no qual marcas, grifes e produtos tecnológicos são as vedetes e buscam formas de inovar e renovar sistematicamente, para atender e retroalimentar um consumo frenético, de caráter hedonista e com distintas éticas socioculturais. (LIPOVETSKY, 2009)

Em uma sociedade globalizada, práticas de comunicação estrategicamente orientadas para a conquista de novos mercados são ferramentas de competitividade fundamentais. Neste mercado, elas passam notadamente pelo discurso sobre a qualidade do vinho, enunciado em publicações especializadas por profissionais do setor, tais como enólogos, sommeliers e experts. À medida que a internet se consolida enquanto um meio de comunicação de dimensões comparáveis às mídias de alcance mais massivo, com mais disponibilidade de acesso à rede e recursos que agilizam e sofisticam suas conexões, inaugurase um modelo de comunicação não-linear e menos verticalizado do que os tradicionais meios ${ }^{2}$. As chamadas redes sociais digitais (facebook, twitter, youtube, whatsapp) são sistemas com interfaces que permitem a construção de uma página pessoal, com exposição pública de seus atores e participação, via comentários, de outros interlocutores. (VITOR \& CABRAL, 2014). Desse 
modo, elas possibilitam e até mesmo estimulam a ocorrência de interações mediadas por computador ou dispositivos móveis (celulares, tablets) e, ainda, estendem aos usuários a possibilidade de facilmente se tornarem produtores de conteúdo, condição antes restrita aos empresários e profissionais midiáticos.

Assim, desde os anos 2000, vemos emergir vários blogs e sites na web, associados às redes sociais, de autoria destes profissionais ou de amantes do vinho, que se habilitaram para realizar um consumo mais ritualizado, seguindo as técnicas de degustação. Os enófilos ${ }^{3}$ se tornaram referências dentro de seus grupos sociais e funcionam como formadores de opinião, já que as ferramentas de comunicação também lhes estão disponíveis.

Esses novos atores da Comunicação começam a impactar de forma significativa as escolhas dos consumidores, à medida que o mercado mundial de vinhos se expande e se diversifica. Seu público é diverso do perfil tradicional, que, no caso brasileiro, mostrava-se essencialmente masculino e elitizado. Jovens, mulheres, amantes da gastronomia buscam referências do vinho adaptadas ao seu cotidiano e, assim, inovadoras em relação aos discursos mais conservadores. Talvez ainda não tão volumoso e efetivo como o mercado de outrora, a produção e o consumo de vinhos se expande pela ação de novos protagonistas, de perfis diferenciados e menos guiados por uma herança geracional de profissão e costumes, conforme a regra predominante até então.

Novos desafios e inovações se impõem em termos dos processos produtivos e das estratégias de comunicação e comercialização, visando o atendimento desses novos perfis de consumidores, dentro de um contexto de globalização. Ter um bom produto apenas não é suficiente, quando se busca êxito num cenário tão competitivo quanto o atual. Pelo contrário, entregá-lo de forma diferenciada, estabelecer diálogo com os formadores de opinião e alimentar a curiosidade neófita são partes desse processo.

Este artigo analisa como esse público recém-iniciado tem nas redes sociais digitais importantes canais de troca e de difusão do gosto pelo vinho e como a combinação entre a livre autoria da internet, o glamour do vinho e o uso das ferramentas de promoção caracterizam a retórica das mensagens veiculadas cotidianamente pela blogosfera do vinho. O material que serve de base para a análise foi colhido em pesquisa de campo junto a atores (produtores, promotores, comerciantes, especialistas) do mercado de vinhos brasileiro e francês entre 2011 e 2013 e acompanhamento contínuo da mídia especializada do vinho de 2011 a 2016, com foco especial às publicações de blogs de vinho brasileiros nos anos de 2015 a 2016, que hoje deve contar com pelo menos 
700 títulos, uma vez que só no portal Enoblogs ${ }^{4}$, há cerca de 600 inscritos.

\section{O vinho « moderno »}

Ao curso da segunda metade do século XX, o mercado mundial de vinhos passa por duas mudanças importantes: de um lado, o consumo de vinhos diminui em países tradicionalmente produtores, como nos países europeus mediterrâneos, na Argentina, entre outros (AGUIAR, 2008). Como já mencionado, Apesar do indiscutível estatuto de bem simbólico, ligado às culturas e às identidades regionais e do crescente refinamento qualitativo alcançado em alguns territórios, o vinho foi perdendo a condição de ser um produto imprescindível à mesa de países como Itália, França e Espanha. Isso se deu notadamente em função das mudanças de comportamento das novas gerações em face da oferta de bebidas alternativas (alcoolizadas ou não), aliada a um marketing mais agressivo da indústria agroalimentar.

Esta tendência de baixa no consumo anual per capita de alguns países começou a se estabilizar a partir dos anos 1980, ainda que persista, com a chegada de novos atores no setor. A moderna enologia, em posse de novas técnicas e tecnologias, vem habilitando vários produtores ao alcance de um padrão de qualidade mediano, bem superior ao rústico vinho de mesa cotidiano de algumas décadas atrás, mesmo para aqueles que inauguram esse tipo de empreendimento. Assim, seguimos com as produções de excelência da vitivinicultura tradicional, referenciais fundadores do vinho de qualidade aperfeiçoado por várias gerações e assistimos à emergência de novos mercados, pouco experimentados, mas que bebem na fonte do saber consolidado do Velho Mundo. O resultado é um nivelamento ascendente daquilo que se produz e consome como vinho mundialmente, em sacrifício da popularização e do volume de vendas e em benefício de um posicionamento do produto enquanto bem de excelência, reservado a ocasiões especiais, de custo médio superior e menos quantitativo.

Em função da entrada crescente de produtores inaugurais, sem a tradicional herança geracional da vitivinicultura e que apostam no negócio enquanto um bom empreendimento - calcado em tecnologias e estratégicas que lhes garantem mais previsibilidade -, o vinho de perfil contemporâneo por vezes é apelidado de "tecnológico" (NIERDELE, 2011). Não obstante, há novas produções que alcançam um reconhecimento especializado e que fogem ao perfil assinalado, ocupando faixas superiores na segmentação hierárquica da qualidade do vinho. Países como Estados Unidos, Austrália, Chile, Nova Zelândia projetam positivamente a vitivinicultura contemporânea e 
inspiram novas gerações de produtores em regiões sem quaisquer históricos vitivinícolas.

Sem entrar nos detalhes técnicos desse realinhamento mundial da produção e consumo de vinhos (AGUIAR, 2015), é importante notar que essa nova concepção busca associar progresso tecnológico a estratégicas de promoção e comercialização para chegar a novos mercados e gerações de consumidores, em termos de idade, região, gênero e poder aquisitivo. Culto ao prazer "aqui e agora", autoprojeções identitárias associadas a uma vontade de se distinguir pelos hábitos de compra, vestimentas, estilos de consumo, entre outros, são alguns dos atributos comportamentais associados ao consumo contemporâneo, que irão, por conseguinte, guiar as novas estratégias produtivas e comerciais.

No caso do vinho, busca-se oferecer um produto cuja promessa seja provocar prazer imediato e intenso, diverso do que se visava pelo consumo tradicional enquanto um elemento de ligação social e acompanhamento da refeição. $\mathrm{Na}$ sua repaginação contemporânea, o mercado de vinhos opta por não se conformar aos modelos mais massivos de expansão das marcas globais, até mesmo por inadequações produtivas, posicionando-se como um nicho de mercado ${ }^{5}$, em muitos aspectos afinados com os bens de luxo, que contemplam consumidores específicos, os quais mantêm com os vinhos uma relação bem particular.

Como avalia Campbell (2006), as demandas do consumidor contemporâneo são correlatas à sua necessidade de criar uma identidade, diante do enfraquecimento das tradicionais referências identitárias da família, da religião ou da nação. Consome-se, então, estilos de vida e um pertencimento temporário a uma identidade grupal. Trata-se de um fenômeno perceptível pela multiplicação de blogs, confrarias, eventos nos quais os consumidores trocam suas impressões e avaliações, compartilham informações e reportam eventos ligados ao mundo do vinho.

O vinho "moderno" é, então, um produto que visa seduzir o seu consumidor, tanto intrinsecamente, por sua cor, brilho, aromaticidade, gosto frutado, quanto extrinsecamente, pela forma da garrafa, design do rótulo e discurso. Com esses atributos, os profissionais do vinho, sejam produtores ou comerciantes, buscam se aproximar mais das preferências estéticas de um público neófito, para, pouco a pouco, transformá-los em consumidores assíduos.

\section{O mercado das singularidades e a profissionalização pelo consumo}

Tradicionalmente, o vinho, embora muito presente na mesa de qualquer 
cidadão de alguns países europeus, especialmente os mediterrâneos, pode ser classificado como uma bebida de elite, que aporta vários simbolismos culturais e tem seu consumo ritualizado, adornado por uma mis-en-scène cerimonial. Se existia um vinho de mesa, havia também o vinho que era servido nos banquetes aristocráticos de várias gerações e essa sua conexão com o que há de mais sofisticado sempre garante ao vinho um glamour, capitalizado pelos consumidores em suas autoprojeções. $\mathrm{O}$ vinho traz notoriedade para aquele que o consome, especialmente em mercados novos, como no Brasil, em que boa parte dos consumidores considera que é necessária uma expertise para beber o vinho fino ${ }^{6}$, diferentemente do popular "vinho de garrafão". A apreciação técnica ou degustação de vinhos, própria dos experts que trabalham na área da Enologia, passa a ser vista como uma premissa para o seu consumo, constrangendo alguns que querem simplesmente bebê-lo, seduzindo outros pela sua riqueza estética e levando à profusão de publicações e cursos que visam habilitar consumidores de vinhos.

Apesar de cada vez mais disponíveis ao grande público em hipermercados e bares, mesmo que em alas e cartas especializadas, o vinho ostenta seu complexo e abstrato linguajar, que faz analogias com percepções olfativas e gustativas de outros produtos, pressupondo profissionais decodificadores, que começam a ocupar as seções das lojas especializadas, para ajustar o que cada produto oferece ao que busca o cliente. Essa "opacidade" de alguns bens - que portam qualidades difíceis de se estabelecer uma medida objetiva de apreciação, requerendo o estabelecimento de bases técnicas validadas consensualmente - caracteriza o que Karpik (2007) denomina "Mercados de Singularidade". O vinho é, portanto, um bem singular, produto pouco massificável, que pode variar de ano a ano, e que, feito com os mesmos ingredientes, pode gerar resultados bem distintos entre produtores. Seus atributos não são facilmente objetiváveis, constituído que é por um evidente componente técnico, que é o da percepção sensorial organoléptica especializada e, assim como qualquer produto agroalimentar, sujeito às subjetividades da apreciação.

Dentro de um quadro de pessoas treinadas para fazer uma leitura interpretativa segundo codificações pré-determinadas, pode haver certo consenso, o que relativiza o caráter subjetivo das impressões pessoais. Isso ocorre nos mercados de arte, serviços especializados, entre outros. O que não é usual é que essa avaliação extrapole o âmbito técnico especializado, como ocorre no mercado de vinhos, em que consumidores sem relação profissional com a área recorrem a esse repertório especializado para escolher e apreciar seus vinhos. Desse modo, atualmente, muitas pessoas se envolvem a tal ponto com a discussão sobre a qualidade e experimentação do vinho, que resolvem 
fazer dessa paixão e passatempo um ofício profissional.

Como o mercado de vinhos só agora se especializa e requer mais profissionais, poucos procuraram diretamente formações afins, como Sommelier e Enologia. A especialização como Sommelier sempre teve um nível técnico no Brasil, ofertada por poucas instituições, com um mercado bem restrito e mal remunerado. A Enologia, por muito tempo teve sua formação oferecida apenas em Bento Gonçalves, RS, tradicional núcleo do mercado de vinhos gaúcho. Assim, o ingresso no universo de vinhos ocorreu muitas vezes por acaso e muitos profissionais se referem à inserção neste mercado como um advento decorrente da paixão pelo tema. Começaram a apreciar os vinhos como consumidores, a participar de eventos e degustações e buscaram se especializar pela leitura e através de pequenas formações, muitas vezes oferecidas pelos próprios importadores e produtores, até montarem um blog temático.

É raro que os blogueiros de vinhos continuem apenas na condição de amantes do tema, uma vez que começam a estabelecer relações profissionais com produtores e importadores do produto objeto de suas falas, tornando-se cada vez mais implicados na constituição do mercado. Os chamados "enófilos" ou "connoisseurs" ganham visibilidade, primeiramente, junto a seu círculo de amigos e, em função da notoriedade que a familiaridade com o ritual e linguajar técnico lhes confere, eles acabam se sobressaindo como referenciais do mercado especializado de vinhos através das redes sociais digitais.

\section{Unidos pelo vinho nas redes sociais}

Caracterizar o consumidor contemporâneo dentro de um perfil objetivo não é uma tarefa simples atualmente, pois ele escapa a modelos estabelecidos, gosta de experimentar novas sensações, podendo corresponder a padrões identitários e socioeconômicos distintos, mesmo que provisoriamente. Atualmente, tanto numa perspectiva do Marketing, quanto em estudos das Ciências Sociais, não se lê o comportamento do consumidor mais como um fenômeno reprodutor das estruturas verticalizadas das estratificações socioeconômicas, nem tampouco de agrupamentos horizontalizados, formados por pessoas que compartilham estilos de vida especulares. Embora passíveis de correspondência, as semelhanças nem sempre mantêm coerências e constâncias. A Teoria dos Meeting Points, de Egeria de Nallo (1999), por exemplo, propõe um foco nos estilos de consumo, em oposição aos estilos de vida, uma vez que eles têm configurações variáveis e temporárias. De acordo com essa tese: "as pessoas assumem determinados estilos de consumo em situações 
especificas; os produtos e marcas transitam entre bolhas, assumindo as características do Meeting Point para dialogar com uma faixa de consumidores.'(GIGLIO, BORGES, CASAQUI, 2006, p.34).

Como dito anteriormente, o vinho fino desfrutou, por muito tempo, no Brasil, do status de uma bebida absolutamente da elite, consumida por pessoas de classe alta, possuidores de adegas, frequentadores da Alta Gastronomia e constantes passageiros internacionais. $\mathrm{Na}$ sua condição atual, a perspectiva elitista permanece, mas há uma nítida expansão para novos segmentos, haja vista a sua disponibilidade crescente em supermercados, restaurantes e bares mais despojados, além de ser um produto que ganha adeptos entre os jovens, com uma abordagem diferenciada da tradicional. Isso leva à ascendência promocional de um marketing mais agressivo, que busca facilitar a assimilação das descrições técnicas dos críticos e das fichas técnicas de vinícolas pelo consumidor através de uma linguagem mais acessível, divertida - sem dispensar o importante diferencial mercadológico do glamour.

Um dos cases mais expressivos do mercado de vinhos brasileiro nos anos 2000 é o da Empresa Wine.com.br ${ }^{8}$ - varejo de vinhos comercializados pela internet, como o próprio nome indica, que inaugurou uma forma de se comunicar com o público alvo extremamente dinâmica, com um texto leve, em português coloquial e visualmente atraente, não apenas pelas características estéticas das mensagens, mas por usar com frequência recursos multimídia e plataformas convergentes. (JENKINS, 2009) Além de baratear o custo dos produtos, em função do formato financeiramente mais enxuto do comércio eletrônico, a empresa foca na experiência do consumidor, com descrições sobre as sensações gustativas e sugestões de harmonizações com pratos (mais utilizadas atualmente para comunicar e promover a qualidade dos vinhos), mas também pela produção de vídeos, viralizados pelo youtube, que valorizam a vivência dos pequenos prazeres, as novas descobertas e a descomplicação do ato de beber vinhos. Esse último aspecto é fundamental num setor que ainda é muito associado a uma linguagem rebuscada, tradicional, bem como a uma perspectiva formal e elitista de consumo.

Desde 2010, a comunicação promocional do vinho leva em conta os novos dispositivos da mídia digital, com uma crescente criação de sites, blogs, aplicativos, meios antes distantes do mundo do vinho. Os blogs temáticos formam hoje uma mídia gigantesca integrada às redes sociais virtuais. As tecnologias digitais da comunicação virtual viabilizam facilmente a midiatização dos produtos em larga escala, favorecendo o fenômeno de globalização do vinho. Todos podem publicar: vinícolas, instituições representativas do setor, versões digitais da imprensa convencional, profissionais especializados ou 
simplesmente amantes do vinho. Todos usam com fartura a web em suas várias possibilidades, como rede social, comércio eletrônico, mídia informativa, entre outros. Este se torna um bom meio para alcançar novos consumidores, pelo baixo custo de produção, permitindo, ainda, a apresentação sequencial da variedade de vinhos que chega ao mercado, acompanhados dos inúmeros pareceres de profissionais do ramo ou de consumidores que se especializaram.

O caminho das redes é estrategicamente interessante para os produtores, uma vez que a difusão hipertextual abre novas trilhas para o mercado e pode tomar grandes proporções, quando qualificadas de forma passional. Além do mais, diante da baixa institucionalização profissional do mercado de vinhos, é difícil avaliar papeis, competências e canais efetivamente vocacionados a um lugar de legitimidade. Para o consumidor leigo do Brasil, que é majoritário, todos aqueles que se prestam a escrever pareceres sobre os vinhos, dada a opacidade da percepção das qualidades deste mercado singular, são dignos de crédito. Fica muito difícil distinguir quem efetivamente é especialista no tema (e tem repertório suficiente para avaliar um vinho) daquele que é seduzido pelos minutos de celebrização que essa combinação entre notoriedade enófila e visibilidade midiática pode facultar pelo aparelhamento das mídias sociais.

Paula Sibília (2006) analisa o fenômeno de multiplicação de dispositivos de comunicação apropriáveis pelos usuários da web e das redes sociais para veiculação de textos e imagens próprios. Os blogs, fotologs, videologs e webcam's de assuntos mais diversos se multiplicam, tendo como autores pessoas comuns que passam a dissertar sobre temas de seu interesse no âmbito de suas redes sociais. Não apenas aqueles que têm por ofício a comunicação passam a habitar um endereço da web como mídia informativa ou promocional, a exemplo das outras mídias. O alcance ampliado das tecnologias de comunicação, disponibilizando ferramentas facilitadoras para a edição de conteúdos por parte de quaisquer leigos democratiza a autoria da comunicação, mas também, em certos casos, banaliza a produção editorial. As peças de comunicação perdem seus valores de obras e são tratadas como veículos de disseminação das personalidades. Fala-se daquilo que se faz e se gosta, de suas próprias impressões sobre a realidade, deixando-se debates e discussões em segundo plano ou com tratamentos bem reducionistas.

Os autores de blogs e outros gêneros confessionais parecem ótimos exemplos dessa nova classe em expansão: os artistas sem obras. Talvez todas essas imagens autorreferentes e esses textos intimistas que hoje atordoam as telas tenham uma meta prioritária: permitir que seus autores se tornem artistas -ou melhor: celebridades. (...) Para ter acesso a tão prezado 
fim, a obra é um elemento importante, mas de segunda ordem, pois o que realmente importa é vida do autor e seus estilo como personagem (SIBILIA, 2006, p.8-9).

O foco está menos no que se diz, no valor do texto, da obra pela qual o autor se expressa e na sua forma de abordá-la. As mensagens são efêmeras e valem menos pelo seu conteúdo do que pela propriedade de despertar atenção, de entreter e de provocar muitos acessos, mesmo que pouco valiosos em termos de contribuição para o tema. Aplicado ao segmento dos vinhos, temos que, em muitos casos, mostrar a frequência a eventos sobre o tema, o acesso a experiências gastronômicas exclusivas, a subentendida habilidade para avaliações de vinhos têm mais relevância do que o conteúdo publicado. O foco está na capacidade de narrar, encantar e espetacularizar a própria existência, enobrecida pelo prestígio do seu objeto de afeição e singularidade. O Blog "Vino Divino Vino", por exemplo, classificado como segundo lugar no Ranking de acessos do Enoblogs, tem uma média de três publicações diárias de posts contendo textos que não extrapolam cinco linhas e em que a imagem ilustrativa ocupa cerca de $70 \%$ da mensagem. As harmonizações muitas vezes apenas indicam o prato e o vinho, sem justificar a escolha e características compatíveis entre ambos.

A importância e visibilidade dos blogs temáticos é hoje incontestável pelos investidores do mercado de vinhos, a despeito de críticas e desconfianças quanto a serem canais dignos da mesma credibilidade dada às mídias tradicionais. Afinal, há pouco mais de uma década no Brasil, o vinho nem sequer era tema pautável e o pouco que se falava estava restrito a algumas páginas de uma ou duas revistas de gastronomia. Hoje, o vinho, com espaço ainda reduzido na mídia convencional, conta com colunas em jornais, minutos da programação das rádios e revistas integralmente voltadas ao assunto. Mas, é na internet e em diferentes dispositivos pelos quais a rede é acessada que a sua comunicação se multiplica em formatos variados e apresenta mais dinamismo, assim como ocorre com outras temáticas. Considerando, ainda, que o vinho é um produto menos massivo, com muitos produtores, estilos variáveis para cada marca, variações entre safras de um mesmo produto, a chegada de novos atores é constante e acompanhada de muitas elucidações e avaliações de qualidades, promovidas pelas próprias empresas e intermediários (veículos especializados, associações voltadas para o tema, especialistas com publicações próprias, guias, confrarias, sites, blogs, comércio eletrônico, páginas redes sociais, etc. $)^{10}$.

A evolução da tecnologia e do volume de informações cresceram de modo tão impressionante nas últimas décadas, que provocaram uma diminuição 
radical do nosso nível de tolerância em relação ao que se pode fazer e obter em certa fração de tempo. Os jornais se tornaram volumosos - incluindo temáticas variadas, cadernos, colunas sobre assuntos os mais diversos -, a rádio e a teledifusão se segmentaram para explorar um assunto freneticamente $24 \mathrm{~h}$ ao dia e a internet, pela sua maior acessibilidade em termos de custos e de produção, tornou-se uma espécie de biblioteca coletiva e ilimitada. Sem as limitações de tempo e custos de produção de veículos impressos, como as revistas especializadas e as colunas de vinhos em jornais, as publicações na web podem ser realizadas e atualizadas rapidamente, além de chegar ao público instantaneamente, espalhando-se vertiginosamente pelas redes sociais. Isso faz com que ela se preste à cobertura da variedade de produtos e eventos do setor, mas requer um fôlego maior também dos autores dessas publicações para fazer essa retroalimentação de um canal do qual se espera constantes inovações e cobertura ilimitada.

Facilitada pelos mecanismos de registros e buscas, tudo deve estar no Google. Se o público espera muito da grande mídia, cria mais expectativas ainda em relação à cobertura temática da internet e essa demanda ilimitada dificilmente pode ser atendida sem muita repetição e baixo nível de profundidade. Há um aumento de recursos para enriquecer as mensagens esteticamente e promover mais difusão e interação, mas as narrativas ficam empobrecidas em sua complexidade, já que o tempo hipermidiático é pouco compatível com processos de elaboração mais longos, bem como com leituras mais reflexivas. "O que aprendi com o Google é que nunca saberei o que deveria saber (...) o Google tem a maior biblioteca do mundo. Mas não é a maior biblioteca de livros, é a maior biblioteca de trechos de citações, de partes e pedaços desconectados.” (DINES, 2015) ${ }^{11}$

Em relação ao mundo do vinho, o fato de muitos blogueiros serem amantes do produto e frequentarem muitos eventos ajuda na diversificação das pautas e como a medida da notoriedade do Blog é o número de acessos, contabilizados e ranqueados por portais de referência no assunto (como o Enoblogs no Brasil), percebemos uma corrida pela novidade e chamadas de impacto para atrair o leitor. Mas a novidade dificilmente indica profundidade. O mais usual é que sejam textos curtos, que prometem mais do que entregam, além de publicações que reproduzem integralmente os press-releases das assessorias de imprensa (profissional comumente contratado pelo mercado de vinhos), e posts a serviço da avaliação sensorial dos vinhos do afluente mercado, que investe pouco em publicidade e mais em nutrir o entusiasmado enófilo especializado de informações, vinhos e experiências enogastronômicas.

Dentro desse perfil, é fato que existem profissionais mais preparados, que exercem funções no setor ou que se tornaram estudiosos do tema e 
conseguem estabelecer limites entre uma relação comercial com as vinícolas para a difusão dos produtos e uma cobertura mais informativa e crítica. Mas nem sempre os blogueiros estão preparados para exercer com propriedade a função de jornalista especializado, pautados por princípios de objetividade, pesquisas sobre fontes e "neutralidade". Esse fenômeno de imbricação entre pautas jornalísticas e interesses promocionais não é novo (AGUIAR, 2008), pelo contrário, muito presente também na mídia convencional, especialmente em espaços e programas voltados para o "colunismo social". Encontramos programas de TV, revistas e jornais praticamente pautados pelos anunciantes sem que essa condição seja assumida publicamente.

Tendo considerado esses aspetos da cobertura midiática do universo do vinho, pode-se dizer que a internet tem contribuído de forma significativa para a difusão do tema e que esses canais podem ser compreendidos enquanto partes indiretas do marketing do vinho, principalmente porque, se não promovem um produto específico diretamente, promovem a paixão pelo tema. Esse tipo de consumidor que interage nos blogs e redes sociais é qualificado, porque tem influência sobre sua rede e age como um formador de opinião. Não se sabe qual a sua participação objetiva na estatística de expansão do número de consumidores de vinhos no Brasil, cujas taxas ${ }^{12}$ ainda evoluem lentamente, tendo em vista que, paralelamente à entrada dos vinhos finos no mercado, há uma retração mundial do consumo de vinhos de mesa, o que gera um impacto negativo em números de produto consumido, mas não de arrecadação. "Consome-se mais e melhor" - uma expressão típica do setor para retratar o perfil do consumo de vinhos contemporâneo. Assim, se no Brasil há uma elevação do consumo per capita, ela deve considerar essa inversão de produtos, que faria a taxa cair, se não fosse a tendência evolutiva do número absoluto de consumidores.

\section{Conclusão}

A comunicação digital virtual facilita os contatos e trocas entre redes longínquas. Os dispositivos móveis, combinando interação e mobilidade, facilitam igualmente os contatos entre produtores, comerciantes e consumidores. Os novos modos de comunicação são apenas parte de um processo de rejuvenescimento do universo do vinho. Após a diminuição do consumo em países tradicionalmente consumidores, essa renovação se estende ao processo de comercialização, suas estratégias promocionais e maneiras de se comunicar com o público. Considerando a entrada do vinho em universos com muito pouca familiaridade com este consumo, uma dessas 
estratégias passa pela formação do consumidor, estimulado pelo glamour desse segmento e tendo como parâmetro de escolhas muitas publicações e sinalizações de especialistas. Assim, há uma crescente multiplicação de produtos midiáticos sobre vinhos em seu marketing global contemporâneo, tendo como receptores consumidores que desenvolvem uma relação de especialização sobre o tema.

Aprende-se a beber vinho e, num mercado jovem como o brasileiro, com poucas formações na área da Enologia, muitos consumidores são os portavozes do mercado, facilitados pelo fenômeno da Blogosfera do vinho, cuja produção de conteúdo é bastante acessível. As redes sociais, com seu formato hipertextual, expandem o consumo dos vinhos, protagonizadas por especialistas de domínio variável sobre o tema, dada a dificuldade da própria interpretação da qualidade do produto e ao fato de que o êxito de um veículo na mídia digital convergente nem sempre é medido pela competência profissional, mas pela capacidade de provocar novos acessos. Num período em que a importância da obra se esvazia, vale a performance da autoria e a sua capacidade de renovação dos discursos curtos e efêmeros, como boa parte do que se evidencia cotidianamente no fluxo contínuo das redes sociais digitais.

Assim, esses novos formatos midiáticos contribuem para a difusão da cultura do vinho, para informações e avaliações que movimentam um mercado que se vale da novidade e variedade de produtos, mas que restam como referências fragmentadas da rotina comercial e promocional do vinho e como um mosaico midiático de celebrização das personalidades que se projetam por meio do emblemático perfil elitista do consumo de vinhos. 


\section{Referências}

AGUIAR, Míriam. A qualidade no consumo do vinho. São Paulo: Ed. Senac São Paulo, 2015. ISBN: 9788539608751.

AGUIAR, Míriam. Preço x qualidade: a complexa equação de um bem diferenciado. In: NIERDELE, P. (org.) Indicações geográficas: qualidade e origem nos mercados alimentares. Porto Alegre: Editora da UFRGS, 2013. (Série Estudos Rurais)

AGUIAR, Míriam. O vinho na era da técnica e da informação: um estudo sobre Brasil e Argentina. Belo Horizonte: Autêntica, 2008.

ALLAIRE, Gilles. L'économie de la qualité, ses secteurs, ses territoires et ses mythes.

INRA (Economie Sociologie Rurales). Toulouse : Éditions scientifiques et médicales Elsevier SAS, 2002.

CAMPBELL, C. Eu compro, logo existo: as bases metafisicas do consumo moderno. In: Cultura, consumo e identidade. Rio de Janeiro: Editora FGV, 2006, p. 49-51.

CCE. Le vin dans le monde à l'horizon 2050 : les enjeux de marché du $21^{\text {ième }}$ siècle Prospectives CCEF. Octobre 2009.

COPELLO, Marcelo. O mercado de vinhos no Brasil. In: Vinhos do Brasil. Rio de Janeiro: Baco Multimídia, 2013, p. 36-41. (b)

DI NALLO, E. Meeting points: soluções de Marketing para uma sociedade complexa. São Paulo: Cobra Editora e Marketing, 1999.

DINES, Alberto. Entrevista com Zygmunt Bauman (2015). Disponível em: http://observatoriodaimprensa.com.br/oitv/entrevista-com-zygmuntbauman/. Acesso em: 18 de janeiro de 2016.

EUROWINE. Vin, internetet réseaux sociaux: une success stories. $\mathrm{N}^{\circ}$ 48. Montpellier, fév- avril 2012, p.30-34.

GARCIA-PARPET, Marie-France. Le terroir, le cépage et la marque: stratégies de valorisation des vins dans un contexte de mondialisation. Cabiers d'economie et sociologie rivales, Paris, v. 60-61, p. 150-180, 2001.

GIGLIO, Eugênio Antônio Maia, BORGES, Silvia, CASAQUI, Vander. Meeting Points: o mercado sob novo enfoque conceitual. São Paulo: Estudos ESPM, 2006, p.31-38.

JENKINS, Henry. Cultura da convergência: a colisão entre os velhos e novos meios de comunicação. Trad. Susana Alexandria. 2ed. São Paulo: Aleph, 2009.

KARPIK, Lucien. L'économie des singularités. Paris: Éditions Gallimard, 2007. 
LIPOVETSKY, Gilles. O império do efêmero: a moda e seu destino nas sociedades modernas. Trad. Maria Lucia Machado. São Paulo: Companhia das Letras, 2009.

NIEDERLE, Paulo. Compromissos para a qualidade: projetos de indicação geográfica para vinhos no Brasil e na França. CPDA, UFRRJ: Rio de Janeiro, 2011. Tese de doutorado.

OIV (2011) World Statistiques : Bilan sur la situation de la vitiviniculture mondiale en 2010. In : 9th General Assembly of the OIV. Porto, 2011

OIV (2007) Situation du secteur vitivinicole mondial en 2007. Statistiques vitivinicoles mondiales. Paris: OIV, 2007.

SIBILIA, Paula. O show da vida intima na internet: blogs, fotologs, videologs e webcams. $15^{\circ}$ Encontro Anual da Compós - Associação Nacional dos Programas de Pós-Graduação em comunicação. UNESP-Bauru, 6 a 9 de junho de 2006. $15 \mathrm{p}$.

TEIL, Geneviève. "Le vin, signe ou probleme?" Communication au congrès de l'AFS, 2005. Consommations \& Sociétés $n^{\circ} 5$. Disponible sur : http://www. argonautes.fr/sections.php?op $=$ viewarticle\&artid $=234$

THOMPSON, John B. A Mídia e a modernidade: uma teoria social da mídia. Trad. Wagner de Oliveira Brandão. 10ed. Petrópolis/RJ: Vozes, 2008.

VITOR, Rhaissa, CABRAL, Adilson. O facebook como foco de oportunidades de branded experience. In: ATEM, Guilherme N., OLIVEIRA, Thaiane M., AZEVEDO, Sandro T. (orgs). Ciberpublicidade: discurso, experiência e consumo na cultura transmidiática. Rio de Janeiro: E-Papers, 2014. P.229-244. 


\section{Notas}

1 O consumo de vinhos na França passou de 170 l per capita, em 1955, a 62,74 1 em 1995, e a 49,66 1 em 2008. Estatísticas disponíveis em: http:/ /www.oiv. int/oiv/info/frpublicationsstatistiques.

2 Enquadro nessa categoria, os jornais, revistas, televisão, rádio, outdoors, entre outros, que constituem aquilo que Thompson (2008) entende como

"Comunicação Mediada" para fugir da expressão "Comunicação de Massa", que carrega outras conotações que não as que ele enumera, como o fato de haver uma dissociação entre emissor e receptores e um fluxo predominantemente de sentido único - de alguns emissores para muitos receptores - nesses modelos.

3 Amantes dos vinhos.

4 No Brasil, o Portal Enoblogs se tornou uma referência da Blogosfera do vinho, uma vez que se tornou uma espécie de Central do tema que lista e dá acesso a todos aqueles que ali se cadastram, criando rankings dos posts mais acessados diariamente. Só nessa rede, existem hoje cerca de 600 cadastrados, além de vários outros independentes. O site californiano Vinography tenta fazer uma compilação de blogs existentes no mundo, pedindo que os autores se comuniquem para serem incluídos em sua lista, com link para as postagens. A relação é dividida por idiomas dos blogs e há 974 blogs listados, sendo que a única que pode se aproximar do número real de blogs é a listagem de blogs em inglês, que inclui 873 títulos. Se tomamos esses números como referências, facilmente se chega a 3000/4000 blogs, caso sejam incluídos os títulos de países com altas taxas de consumo, como França, Itália, Alemanha, Inglaterra.

5 Em administração, e marketing, nicho é a porção específica de um mercado, geralmente uma parte pequena, com necessidades e hábitos específicos. 6 Vinho feito a partir de uvas viníferas, denominadas também "europeias", diferente do tradicional vinho de mesa brasileiro, que é feito a partir de uvas denominadas "americanas", devido à sua origem norte-americana, e que seria mais apropriado à produção de sucos, segundo o meio especializado.

7 Consumidores quase especialistas, que consomem e conhecem muitos vinhos.

8 https://www.wine.com.br/

9 MARQUES, Elmano. Vinho Divino Vino. Disponível em: http://blog. tribunadonorte.com.br/vinodivinovino. Acesso em: 24 de maio de 2016.

10 Segundo reportagem da EUROWINE (2012) sobre as redes sociais e o vinho, um estudo da Wine Intelligent mostra que $20 \%$ dos consumidores britânicos consultam os Coups de Caur dos blogueiros. Uma enquete Survey realizada pela Agencia Francesa de Internet Sowine junto a 1200 pessoas com idades entre $18 \mathrm{e}$ 65 anos, mostra que a internet e as novas tecnologias se colocam em 5o lugar dos meios de pesquisa de informação para os consumidores franceses ; seguidos pelos cavistas $(34,6 \%)$, sommeliers $(15,3 \%)$, trocas diretas com os produtores $(14 \%)$, guias $(7,7 \%)$ e, enfim, a imprensa escrita especializada ou generalista $(4,4 \%)$. 11 Trecho de entrevista com Zygmunt Bauman, concedida ao Observatório da Imprensa - Programa número 790.

12 A Média de consumo anual de vinhos per capita do Brasil transita entre 1,8 e 21 há algumas décadas, com alteração significativa nos últimos anos quanto aos tipos de vinho, consumidores e regiões de consumo. Há uma concentração do consumo nas regiões Sul e Sudeste. 